\title{
Guidelines
}

European

Thyroid Journal
Eur Thyroid J 2012;1:55-71

DOI: $\underline{10.1159 / 000339444}$
Received: March 30, 2012

Accepted after revision: May 7, 2012

Published online: June 13, 2012

\section{ETA Guidelines: The Use of L-T4 + L-T3 in the Treatment of Hypothyroidism}

\author{
Wilmar M. Wiersinga ${ }^{a} \quad$ Leonidas Duntas $^{\mathrm{b}} \quad$ Valentin Fadeyev $^{\mathrm{c}} \quad$ Birte Nygaard $^{\mathrm{d}}$ \\ Mark P.J. Vanderpump ${ }^{\mathrm{e}}$ \\ aDepartment of Endocrinology and Metabolism, Academic Medical Center, University of Amsterdam, \\ Amsterdam, The Netherlands; ${ }^{b}$ Endocrine Unit, Evgenidion Hospital, University of Athens Medical School,

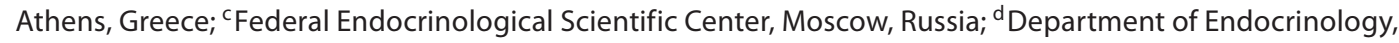 \\ Herlev Hospital, Herlev, Denmark; ' Department of Endocrinology, Royal Free Hampstead NHS Trust, London, UK
}

\section{Key Words}

Hypothyroidism - Treatment - Thyroxine •

Triiodothyronine $\cdot$ Combination therapy $\cdot$ Guidelines

\begin{abstract}
Background: Data suggest symptoms of hypothyroidism persist in 5-10\% of levothyroxine (L-T4)-treated hypothyroid patients with normal serum thyrotrophin (TSH). The use of L-T4 + liothyronine (L-T3) combination therapy in such patients is controversial. The ETA nominated a task force to review the topic and formulate guidelines in this area. Methods: Task force members developed a list of relevant topics. Recommendations on each topic are based on a systematic literature search, discussions within the task force, and comments from the European Thyroid Association (ETA) membership at large. Results: Suggested explanations for persisting symptoms include: awareness of a chronic disease, presence of associated autoimmune diseases, thyroid autoimmunity per se, and inadequacy of L-T4 treatment to restore physiological thyroxine (T4) and triiodothyronine (T3) concentrations in serum and tissues. There is insufficient evidence that L-T4 + L-T3 combination therapy is better than L-T4 monotherapy, and it is recommended that L-T4 monotherapy remains the standard treatment of hypothyroidism.
\end{abstract}

L-T4 + L-T3 combination therapy might be considered as an experimental approach in compliant L-T4-treated hypothyroid patients who have persistent complaints despite serum TSH values within the reference range, provided they have previously received support to deal with the chronic nature of their disease, and associated autoimmune diseases have been excluded. Treatment should only be instituted by accredited internists/endocrinologists, and discontinued if no improvement is experienced after 3 months. It is suggested to start combination therapy in an L-T4/L-T3 dose ratio between 13:1 and 20:1 by weight (L-T4 once daily, and the daily L-T3 dose in two doses). Currently available combined preparations all have an L-T4/L-T3 dose ratio of less than 13:1, and are not recommended. Close monitoring is indicated, aiming not only to normalize serum TSH and free T4 but also normal serum free T4/free T3 ratios. Suggestions are made for further research. Conclusion: L-T4 + L-T3 combination therapy should be considered solely as an experimental treatment modality. The present guidelines are offered to enhance its safety and to counter its indiscriminate use.

Copyright $\odot 2012$ European Thyroid Association Published by S. Karger AG, Basel

Authors represent the task force for these guidelines, instituted by the ETA Executive Committee and Guidelines Board.

\section{KARGER}

Fax +41613061234

E-Mail karger@karger.ch

www.karger.com (c) 2012 European Thyroid Association

Published by S. Karger AG, Basel

2235-0640/12/0012-0055 $\$ 38.00 / 0$

Accessible online at:

www.karger.com/etj
Wilmar M. Wiersinga

Department of Endocrinology and Metabolism

Academic Medical Center, University of Amsterdam, Meibergdreef 9

NL-1105 AZ Amsterdam (The Netherlands)

E-Mailw.m.wiersinga@amc.uva.nl 


\section{Introduction}

Hypothyroidism is a condition characterized by the clinical and biochemical manifestations of thyroid hormone deficiency in the target tissues of thyroid hormone. The most common cause of hypothyroidism is deficient production of thyroid hormones by the thyroid gland. Thyroxine (T4) is produced exclusively by the thyroid gland; its daily production rate is about $100 \mu \mathrm{g}$ at an average body surface area of $1.79 \mathrm{~m}^{2}\left(56.2 \mu \mathrm{g} / \mathrm{day} / \mathrm{m}^{2}\right)$. Daily production rate of triiodothyronine (T3) for a body surface area of $1.79 \mathrm{~m}^{2}$ is about $29 \mu \mathrm{g}\left(16 \mu \mathrm{g} / \mathrm{day} / \mathrm{m}^{2}\right): 20 \%$ $\left(\sim 6 \mu \mathrm{g}\right.$, or $\left.3.3 \mu \mathrm{g} / \mathrm{day} / \mathrm{m}^{2}\right)$ is secreted by the thyroid gland, and $80 \%\left(\sim 23 \mu \mathrm{g}\right.$, or $\left.12.7 \mu \mathrm{g} / \mathrm{day} / \mathrm{m}^{2}\right)$ is generated in extrathyroidal tissues by $5^{\prime}$-deiodination of T4 [1].

Treatment of hypothyroidism is today predominantly with L-T4: its long half-life of 1 week is advantageous allowing one daily dose and it generates stable T3 levels by conversion of T4 into T3 in peripheral tissues. In contrast, the half-life of T3 is short (about 1 day), and treatment with L-T3 would require several doses per day with wide variation in serum T3 levels along the 24 -hour period. Elevated serum T3 concentrations may occur during the absorption of L-T3 which can be associated with symptoms of tachycardia and nervousness. The options of treatment with L-T3 or the combination of L-T4 and L-T3 therefore have largely been abandoned $[2,3]$. However, recent developments have rekindled interest in the potential advantages of L-T4 + L-T3 combination therapy over L-T4 monotherapy. On the one hand, many practising physicians have the experience that some of their hypothyroid patients have persistent complaints, despite adequate treatment with L-T4 as evident from normalization of TSH, free T4 and T3 concentrations. The creation of special interest groups like that of 'Hypo but not Happy' patients attests this point [4]. A recent randomized clinical trial reported a clear preference of patients for L-T4 + L-T3 combination therapy over L-T4 monotherapy [5].

In recognition of these developments and existing controversies regarding the value of $\mathrm{L}-\mathrm{T} 4+\mathrm{L}-\mathrm{T} 3$ combination therapy of hypothyroidism, the ETA appointed a task force to systematically approach this issue and establish guidelines according to the principles of evidence-based medicine. The task force acknowledged that L-T4 + L-T3 combination therapy is a highly controversial issue. In fact, as evident from the recommendations in this report, the evidence base to advocate this treatment modality is very limited indeed. Nevertheless, the presently proposed guidelines aim to provide guidance on how to explore persisting symptoms in a systematic manner. They stipulate that combination therapy should be viewed solely as experimental. They recommend much lower L-T3 doses in combination therapy than previously used, thereby enhancing safety. And they show that the thyroid community at large does care about the issue of persistent symptoms. The guidelines should not lead to the indiscriminate use of L-T4 + L-T3 combination therapy; in contrast, the recommendations made should help physicians to identify the relatively few L-T4treated hypothyroid patients who might benefit from a carefully executed trial with L-T4 + L-T3 combination therapy.

\section{Methods}

The ETA Executive Committee nominated a task force for the development of guidelines for the treatment of hypothyroidism with the combination of L-T4 and L-T3. Task force members declared whether they had any potential conflict of interest. Funding was derived solely from the general funds of the ETA and thus the task force functioned without commercial support.

The task force excluded from the present analysis papers on L-T4 + L-T3 combination therapy in central hypothyroidism, in children, and in hepatic hemangioma; investigations were restricted to papers on adults with a definite diagnosis of primary hypothyroidism, evaluating preferentially randomized clinical trials rather than observational studies. The task force first developed a list of the relevant topics in this area. Two task force members were assigned to review the literature relevant to each of the topics, using a systematic PubMed, Embase and Medline search for primary references and reviews published until September 2011. A preliminary document and a series of recommendations concerning the topics were generated by each subgroup and then critically reviewed by the task force at large. Task force deliberations took place mostly through electronic communication; there were telephone conferences and one final committee meeting. The recommendations are based on consensus of task force members which was unanimous.

The guidelines were developed to combine the best scientific evidence with the experience of seasoned clinicians and the pragmatic realities inherent in implementation [6]. Recommendations are rated according to the GRADE system $[7,8]$. The GRADE system classifies recommendations into one of two grades: strong recommendations receive a grade 1 classification using the term 'we recommend', weak recommendations receive a grade 2 classification using the term 'we suggest'. The quality of the evidence for the recommendations can be +00 (low, grade $\mathrm{C}$ ), ++0 (moderate, grade $\mathrm{B}$ ), and +++ (high, grade $\mathrm{A}$ ). The draft guidelines were put on the 'Members-only' section of the ETA website for 1 month, in order to receive comments of ETA members. The final document was approved by the Guidelines Board and the Executive Committee of the ETA. 


\section{Results}

Is There an Unmet Need in L-T4-Treated Hypothyroid Patients?

Every experienced clinician knows that there are some patients with L-T4-treated hypothyroidism who do not recover completely [9]. Dissatisfaction with outcome of L-T4 monotherapy is often expressed on websites of thyroid patient associations $[4,10]$. There are, however, just a few controlled studies which have evaluated dissatisfaction and remaining complaints in a quantitative manner.

In a community-based study from the UK, 381 patients who had been on L-T4 for a minimum of 4 months and had normal serum TSH values (local reference ranges were $0.1-5.5$ or $0.2-6.0 \mathrm{mU} / \mathrm{l}$ ) were compared with 535 age- and sex-matched controls [11]. Two questionnaires were used: the General Health Questionnaire (GHQ-12) to detect psychological distress of unspecified nature, and a 12-question Thyroid Symptom Questionnaire (TSQ). A score of three or more indicated caseness. After correction for age, sex, chronic diseases and chronic medication, the proportion of caseness was higher in patients than in controls, both in the GHQ-12 (34.4 vs. $25.6 \%, \mathrm{p}=0.012$, odds ratio (OR) 1.48 [1.09-2.00]) and in the TSQ (48.6 vs. $35.0 \%, \mathrm{p}<0.001$, OR 1.71 [1.29-2.25]). Limiting the analysis to patients with serum TSH in a narrow normal range $(0.4-4.0 \mathrm{mU} / \mathrm{l})$ gave similar outcomes: caseness was $35.1 \%$ in GHQ- 12 and $48.5 \%$ in TSQ. The study provided evidence that patients on L-T4 replacement even with a normal serum TSH display significant impairment of psychological well-being compared to controls of similar age and sex. Serum-free T4 (but not free T3) showed a negative relation to GHQ-12 scores (higher free T4 was associated with lower GHQ-12 scores implying improved well-being), whereas a positive correlation was seen with TSH and GHQ [12]. Similar correlations were seen with TSQ, but not with Hospital Anxiety and Depression Scale (HADS) scores. Another community-based study from The Netherlands investigated 141 patients who had been on L-T4 replacement for primary autoimmune hypothyroidism for at least 6 months and had serum TSH values between 0.11 and 4.0 $\mathrm{mU} / 1$ [13]. Results of neurocognitive tests (cognitive or psychomotor speed, attention, working memory as well as learning and memory) and scores on questionnaires (Symptom Check List-90 total score and the Rand 36item Health Survey subscales for mental health and vitality) of patients were compared with reference values of these tests for the Dutch general population. Patients showed poor performance on various domains of neurocognitive functioning compared with standard reference values ( $p=0.001$ ), especially on a complex attention task and on verbal memory tests. Levels of well-being were significantly lower for patients compared with those of the general population $(\mathrm{p}=0.001)$. Neither serum TSH nor anti-thyroid antibodies were determinants of neurocognitive functioning or well-being. The results of this study suggest that neurocognitive functioning as well as psychological well-being may not be completely restored in patients with hypothyroidism despite L-T4 treatment.

A third community-based study from Norway among subjects aged $\geq 40$ years compared HADS scores of 1,546 women on L-T4 and 18,137 women without thyroid disease not on L-T4 [14]. Serum TSH (median values with interquartile range) in both groups were 1.25 (0.3-2.9) and $1.5(1.1-2.1) \mathrm{mU} / \mathrm{l}$, respectively. More women on L-T4 had high scores (HADS $\geq 8$ ) for depression and anxiety than women not on L-T4: depression 18.4 versus $12.8 \%$ $(\mathrm{p}<0.001)$, anxiety 23.4 versus $18.6 \%(\mathrm{p}<0.001)$, respectively. In women on L-T4, serum TSH was positively associated with depression and anxiety. For each $1 \mathrm{mU} / \mathrm{l}$ increase in serum TSH there was $3 \%$ more depression cases $(p=0.04)$ and $3 \%$ more anxiety cases $(p=0.046)$. In women not on L-T4, no significant associations with depression or anxiety were seen. The study suggested a higher prevalence of depression and anxiety in L-T4treated hypothyroid women of 40 years and older.

The few other studies on this topic are limited by their small sample size. In a population-based study of middleaged women in Sweden, 29 women were identified who were treated with L-T4. Twelve years later, 22 of them still used L-T4 and had normal serum TSH values. Their quality of life was not different from 968 women from the population without thyroid disease [15]. In a study from the USA recruiting women mostly by advertisement, 34 L-T4treated subjects had decrements in health status, psychological function, working memory, and motor learning compared to 22 euthyroid controls. There were no correlations between serum TSH levels and outcomes [16].

In each of the three large cross-sectional observational studies, the prevalence of particular health problems was higher in L-T4-treated hypothyroid patients than in controls. This was also true if the analyses were restricted to patients with normal serum TSH values. The observed health problems were related to psychological distress, thyroid symptoms, neurocognition, general well-being, depression and anxiety. The strengths of the papers are their community-based study design and the large sample size. As all outcomes point into the same direction, 
Table 1. Possible causes of persistent complaints in L-T4-treated hypothyroid patients

I Nonspecific causes: related to the chronic nature of the disease

II Specific causes: related to thyroid disease and thyroid

hormone replacement

1 Associated autoimmune diseases

2 Thyroid autoimmunity per se

3 Inadequacy of L-T4 dose

4 Inadequacy of L-T4 treatment modality

one may conclude that there is indeed an unmet need in L-T4-treated hypothyroid patients. The dimension and causality of the problem is not clear. In this respect it is noteworthy that hypothyroid symptoms were reported, despite a normal serum TSH, by $12.1 \%$ of 22,842 participants (1,525 of which were taking thyroid medication) in the Colorado Thyroid Disease Prevalence Study [17]. Although the magnitude of the problem is limited, the suboptimal outcome of L-T4 treatment might be very relevant for individual patients. Based on the frequency differences between patients and controls, about $10 \%$ of L-T4-treated hypothyroid patients have impaired psychological well-being and about 5\% depression or anxiety which can be related to the disease and L-T4 therapy.

\section{Recommendations}

(1) In L-T4-treated hypothyroid patients with normal serum TSH values, psychological distress, impaired wellbeing and cognitive disturbances occur more often than in controls $(1 /+00)$.

(2) Data suggest that $5-10 \%$ of L-T4-treated hypothyroid patients with normal serum TSH have persistent symptoms which can be related to the disease and L-T4 therapy $(2 /+00)$.

\section{Is There a Biologic Rationale for Persistent Complaints in L-T4-Treated Hypothyroid Patients?}

There are a number of possible explanations for persistent symptoms in L-T4-treated hypothyroid patients (listed in table 1). It is assumed that a general work-up has already excluded well-known causes of nonspecific symptoms and 'unwellness' that have nothing to do with thyroid diseases such as anaemia, hypercalcemia, occult infections, etc.

Most if not all hypothyroid patients on L-T4 treatment will require lifelong replacement therapy with thyroid hormones. Transient thyroid hormone deficiency is rare.
Thus, in most instances to have hypothyroidism means to have a chronic disease. Awareness of having a chronic disease and to be dependent on thyroid hormone medication for the remaining part of one's life could make patients feel unhappy and less healthy $[9,10,18,19]$. The necessity of regular medical visits may cause discomfort and a feeling of 'unwellness'. Patients with nonspecific symptoms like fatigue may be inclined to attribute such complaints to the disease and its treatment. Persistent nonspecific complaints are reported in many chronic endocrine and nonendocrine diseases.

Hypothyroidism is most frequently caused by chronic autoimmune thyroiditis (Hashimoto's disease) and by thyroid ablation in Graves' disease. Most hypothyroid patients thus have autoimmune thyroid disease. It is well known that autoimmune thyroid disease is associated with other autoimmune diseases [20,21]. In a large UK study the frequency of other autoimmune disorders was 9.67\% in 2,791 patients with Graves' disease, and $14.3 \%$ in 495 patients with Hashimoto's disease [22]. Rheumatoid arthritis was the most common coexisting autoimmune disorder (found in 3.15\% of Graves' disease and $4.24 \%$ of Hashimoto's disease). Relative risks of almost all other autoimmune diseases were significantly increased ( $R R>10$ for pernicious anaemia, systemic lupus erythematosus, Addison's disease, celiac disease, and vitiligo). Many of these conditions may go unnoticed for a long time in view of the nonspecific nature of associated symptoms. Screening for other autoimmune diseases has been recommended in subjects with autoimmune thyroid disease presenting with new or nonspecific symptoms [22].

Thyroid peroxidase antibodies (TPO-Ab) in serum are a marker of autoimmune thyroid disease. TPO-Abs are very prevalent in the general population and also in subjects with normal TSH values. The large populationbased HUNT study in Norway did not observe a relationship between TPO-Ab and depression or anxiety after adjustment for age, gender and TSH [23]. In contrast, a Dutch community-based study of 583 randomly selected perimenopausal women reports an association between TPO-Ab >100 kU/l and depression (OR 3.0, 95\% CI 1.36.8); neither thyroid dysfunction nor menopausal status was related to depression [24]. A study from Austria investigated 426 euthyroid women undergoing thyroid surgery for benign thyroid diseases [25]. The diagnosis of Hashimoto's thyroiditis in 28 patients was based on the histology of the surgical specimen, and strongly related to TPO-Ab $>121 \mathrm{kU} / \mathrm{l}$. Patients with TPO-Ab >121 kU/l had higher rates for several symptoms including chronic fatigue, dry hair, chronic irritability, chronic nervousness 
and lower quality of life (SF-36 questionnaire) than those patients with $\mathrm{TPO}-\mathrm{Ab}<121 \mathrm{kU} / \mathrm{l}$; there was no difference in serum TSH levels or the use of thyroid hormone replacement therapy (29\%) between both groups. These data suggest the possibility that thyroid autoimmunity per se, independent of thyroid function, contribute to symptoms and decreased quality of life.

Pharmacological issues such as decreased intestinal absorption of L-T4 or interference with other drugs may necessitate adjustment of the L-T4 dose, but an adequate L-T4 dose will eventually normalize serum TSH values in all patients with primary hypothyroidism (assuming compliance with the medication). It has been questioned whether L-T4 doses that normalize serum TSH are really adequate. The peripheral conversion of T4 into T3 makes it possible to achieve normal serum T3 concentrations in humans treated with L-T4 [26], but it is argued that the T3 levels observed might be lower than the T3 levels in the premorbid state. This possibility has been evaluated in a study comparing thyroid function in the same patients before and after total thyroidectomy for goiter, benign nodular thyroid disease or thyroid cancer [27]. Patients were euthyroid before surgery without medication and after surgery with L-T4 medication. Pre- and postoperative serum TSH (1.18 \pm 0.58 vs. $1.30 \pm 1.89 \mathrm{mU} / \mathrm{l})$ and serum T3 (1.99 \pm 0.41 vs. $1.96 \pm 0.43 \mathrm{nmol} / \mathrm{l})$ concentrations were not different.

Another suggestion has been that well-being is optimized by fine adjustment of L-T4 dosage, aiming for a serum TSH in the lower reference range [28]. This has been investigated in a double-blind RCT with a crossover study design, in which each of the 52 L-T4-treated hypothyroid patients received three L-T4 doses in random order for eight weeks: low dose, middle dose $(25 \mu \mathrm{g}$ more than low dose), and high dose ( $25 \mu \mathrm{g}$ more than middle dose), resulting in serum TSH values of $2.8 \pm 0.4,1.1 \pm$ 0.2 and $0.3 \pm 0.1 \mathrm{mU} / \mathrm{l}$, respectively $(\mathrm{p}<0.001)$ without changes in body weight [29]. These small changes in L-T4 dosage did not produce measurable changes in hypothyroid symptoms, well-being, quality of life, or cognition, and no significant treatment preference was observed. These data do not support the suggestion that the target serum TSH range for the treatment of hypothyroidism should differ from the laboratory reference range.

Normalization of serum TSH and T3 concentrations is achieved with L-T4 therapy at the expense of higher serum free T4 concentrations than normal $[26,27]$. As a result, the ratio of serum free $\mathrm{T} 4$ to serum free $\mathrm{T} 3$ concentrations in L-T4-treated hypothyroid patients is higher than in healthy subjects. L-T4 therapy thus fails in precisely mimicking the physiological serum free T4 to free T3 ratio.
Whether or not this has functional consequences in humans is unknown. Serum thyroid hormone concentrations are related to $\mathrm{T} 3$-dependent gene expression only to a certain extent, as bioavailability of $\mathrm{T} 3$ to its nuclear receptors is modified by specific thyroid hormone transporters in the plasma membrane and cellular deiodinases which locally may activate or inactivate thyroid hormone [30]. There is wide variation in how tissues handle thyroid hormones. In rat liver, for example, plasma-derived T3 and T3 generated locally from T4 via deiodinase type 1 (D1) are in different compartments with respect to nuclear receptor binding: practically all of the nuclear T3 appears to be plasma derived [31]. In contrast, in tissues like brain most of T3 available for receptor binding is locally produced from T4 via deiodinase type 2 (D2). In hypothyroidism, liver D1 activity is decreased but brain D2 activity is increased. Such tissue-specific regulatory mechanisms may jeopardize simultaneous normalization of thyroid hormone concentrations in all hypothyroid tissues.

Administration of L-T4 alone to thyroidectomised rats does not, at any dose tested, result in normal T4 and T3 concentrations simultaneously in all tissues (which can be taken as one criterion for defining euthyroidism) [32]. The L-T4 dose needed to normalize thyroid hormone concentrations was different for each tissue, and supraphysiological T4 concentrations had to be reached in most tissues to normalize their T3 concentrations. Only the combined treatment with L-T4 and L-T3 resulted in normal T4 and T3 concentrations in plasma and all tissues as well as normal serum TSH and near-normal D1 and D2 activities [33]. The addition of small doses of L-T3 decreased the amount of L-T4 needed to normalize T3 in the majority of tissues by about $50 \%$ compared to the amount necessary when L-T4 alone is used. Combination therapy ensuring euthyroidism in all tissues at the same time was only obtained at a dose of $0.90 \mu \mathrm{g}$ T4 and 0.15 $\mu \mathrm{g}$ T3 per $100 \mathrm{~g}$ body weight per day; the molar ratio of the $\mathrm{T} 4$ and $\mathrm{T} 3$ dose is $5: 1$, similar to that present in the normal thyroidal secretion of the rat.

When extrapolating these observations in rats to humans, one should realize that the relative importance of thyroidal T3 secretion versus extrathyroidal T3 generation from T4 is greater in rats than in humans. The molar ratio of T4 to T3 in thyroidal secretion is $\sim 5.7: 1$ in rats and $\sim 14: 1$ in humans [1]. Nevertheless, the rat findings suggest the possibility that the treatment modality with L-T4 alone might be inadequate.

The list of possible explanations for persistent symptoms is not complete. The normal thyroid gland may secrete also compounds like thyronamines and 3,5-T2; one 
could speculate whether a postulated diminished secretion of these compounds in primary hypothyroidism is somehow involved in persisting symptoms. Another possibility is that subjects with depression or a general sense of lack of well-being may be more likely to be screened, diagnosed and treated for hypothyroidism. Thus, subjects being generally dissatisfied with their state of health will be over-represented in patients receiving L-T4 treatment, and any persistent complaints may be wrongly attributed to L-T4 treatment $[78,79]$.

\section{Recommendations}

(3) Suggested explanations for persistent symptoms in L-T4-treated hypothyroid patients despite normalization of serum TSH, include: awareness of a chronic disease, presence of associated autoimmune diseases, thyroid autoimmunity per se (independent of thyroid function), and inadequacy of L-T4 treatment to restore physiological $\mathrm{T} 4$ and $\mathrm{T} 3$ concentrations in serum and tissues $(2 /+00)$.

\section{Is There Evidence that L-T4 $+\mathrm{L}$-T3 Combination Therapy Serves the Hypothyroid Patient Better than L-T4 Monotherapy?}

\section{Meta-Analysis of RCTs}

In 2006, a meta-analysis was published of 11 clinical studies in which 1,216 adult hypothyroid patients on L-T4 treatment were randomized to receive L-T4 monotherapy or L-T4 + L-T3 combination therapy [34]. The meta-analysis found no difference in the effectiveness of combination versus monotherapy in any of the following items: bodily pain (standardized mean difference SMD 0.00, 95\% CI -0.34, 0.35), depression (SMD 0.07, 95\% CI -0.20, 0.34 ), anxiety (SMD $0.00,95 \% \mathrm{CI}-0.12,0.11$ ), fatigue (SMD $-0.12,95 \%$ CI $-0.33,0.09$ ), quality of life (SMD $0.03,95 \%$ CI $-0.09,0.15)$, body weight, total serum cholesterol, triglycerides, low-density lipoprotein, and highdensity lipoprotein. Adverse events did not differ between regimens (RR 1.19, 95\% CI 0.63, 2.24). The authors of the meta-analysis concluded: 'It is doubtful whether further trials evaluating combination therapy are needed because the chances that the accumulated evidence will change are low'. A more recent systematic review in 2009 reached similar conclusions [35]. However, a recent RCT observed combination therapy was superior to monotherapy [5]. So do we need still more trials? [36]. We evaluated all available studies to look for possible bias and confounding factors.

\section{Critical Review of RCTs}

Table 2 lists the 13 RCTs published so far, ranked by sample size. All RCTs are double-blind in nature. The earliest study from 1970 [37] and the most recent one from 2009 [5] are not included in the meta-analysis, but all other studies (performed between 1999 and 2005) are included in the meta-analysis [34]. One study is available only in abstract form [38].

\section{Sample Size}

A formal sample size calculation is reported in seven studies [5, 39, 41, 42, 45-47]. It is obvious that a low sample size limits the power to detect differences between treatment arms. The largest sample sizes are associated with recruitment from primary care [39, 40].

\section{Recruitment}

In the recruitment of patients it is important to avoid selection bias: participation to RCTs should reflect the general population of L-T4-treated hypothyroid patients. This is best guaranteed by inviting all eligible patients in a community population as done in three studies [39-41]. Recruitment by advertisement carries the risk to include a disproportionate number of patients dissatisfied with the outcome of L-T4 treatment. Indeed, participants responding to advertisements were dissatisfied in 55\% in one study [41] and had depressive symptoms in $100 \%$ in another study [43]. One can counter that inclusion of such patients is not disadvantageous because the very end of L-T4 + L-T3 combination therapy is to improve wellbeing of patients with persistent symptoms on L-T4 monotherapy. It is thus relevant to evaluate whether baseline dissatisfaction or mood state are associated with outcomes. This has been done in five studies: results were not different in patients with or without depression [44], in patients in the highest tertile of the psychiatric Symptoms Checklist [40], in patients with high or low fatigue levels [45], or in dissatisfied patients at baseline [41]. In one study, patients preferring combination therapy had worse baseline scores for depression and social functioning than patients without preference [5].

\section{Cause of Hypothyroidism}

Although Hashimoto's thyroiditis was the most common cause of primary hypothyroidism in the RCTs, many studies included patients with hypothyroidism due to thyroidectomy or radioiodine (131I) therapy performed because of Graves' hyperthyroidism, benign goiter or thyroid cancer. This may constitute a bias, as the benefit of 


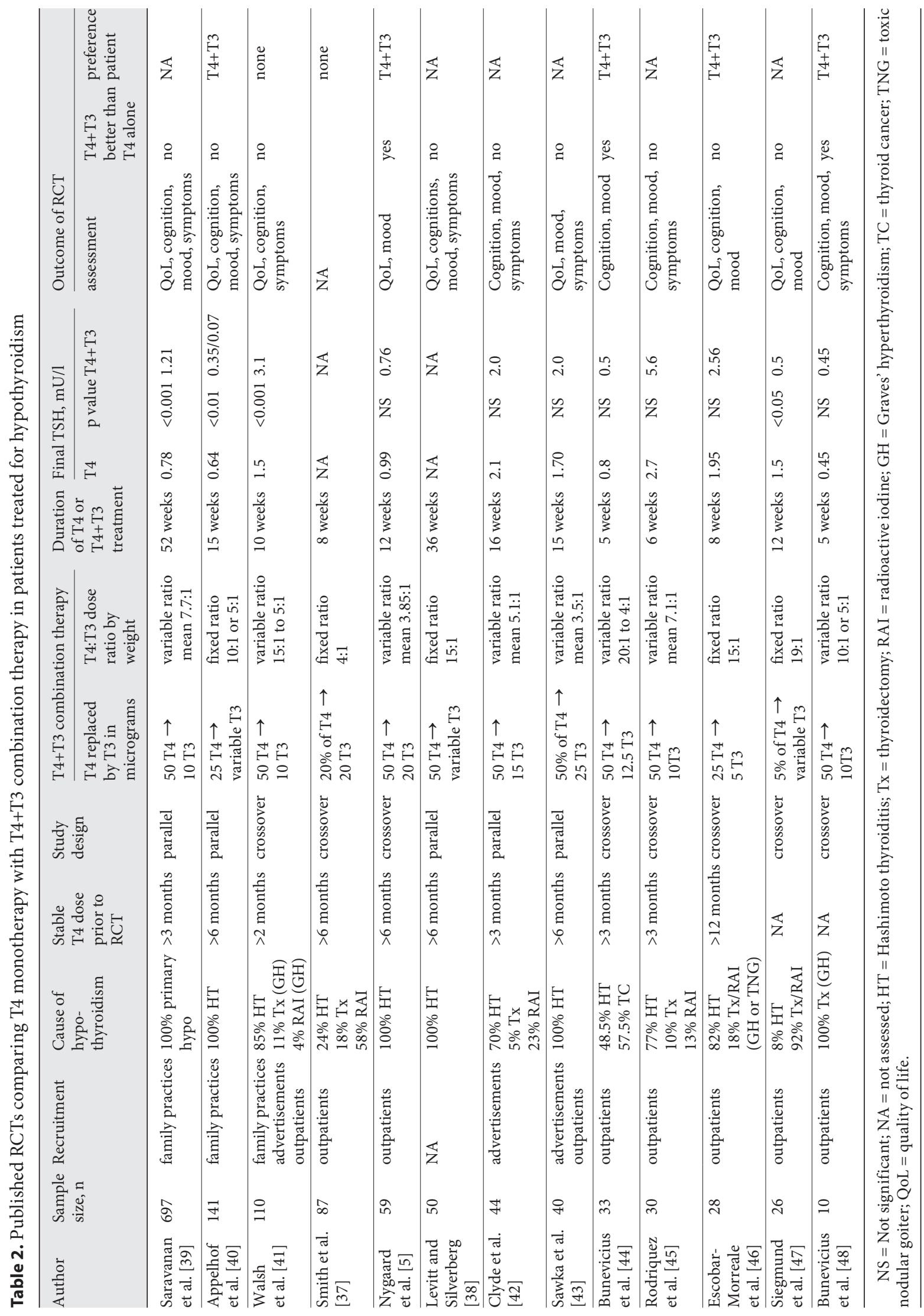


combination therapy in one trial was observed only in the thyroid cancer patients and not in patients with autoimmune thyroiditis [48, 49]. However, another study could not detect differences in outcome between patients with autoimmune hypothyroidism compared with postsurgical and postradioiodine hypothyroidism [41]. The metaanalysis was unable to demonstrate a relation between the proportion of athyreotic patients included in the study and the effect of combination therapy on symptoms [34].

\section{Stable L-T4 Dose Prior to Randomization}

Hypothyroid patients had been on a stable L-T4 replacement dose for at least 2 months in all RCTs. One trial which randomized untreated hypothyroid patients to receive $\mathrm{L}-\mathrm{T} 4$ or $\mathrm{T} 4+\mathrm{T} 3$ demonstrated no differences in the course of thyroid symptoms between both treatment arms [50]. In view of the aberrant study design this RCT is not included in table 2.

\section{Study Design}

Five studies have a parallel study design and eight a crossover study design. The disadvantage of parallel studies is the need for a larger sample size in comparison to crossover studies in order to reach the same power of the study. The disadvantage of crossover studies is that observations may not be independent because the same patients receive both combination and monotherapy. There could be a significant carry-over effect, especially when assuming biological effects of thyroid hormones in tissues like brain may have a long duration. A wash-out period can be inserted between the two treatment periods, but this has been done in just one study [41]. A significant carry-over effect was not observed in the studies which tested specifically for its presence $[5,41,45,46]$. Moreover, the metaanalysis observed similar effects on outcome parameters when comparing parallel and crossover designs [34].

\section{L-T4 + L-T3 Combination Therapy}

Whereas patients randomized to receive L-T4 monotherapy continued their usual L-T4 dose, in patients randomized to receive L-T4 + L-T3 combination therapy, a part of their L-T4 dose was replaced by L-T3. Most frequently a fixed amount of L-T4 $(50 \mu \mathrm{g})$ was replaced by a fixed amount of L-T3 $(10,12.5,20$ or $25 \mu \mathrm{g})$, resulting in a variable ratio of administered $\mathrm{T} 4$ to $\mathrm{T} 3$ dose by weight in each of these studies. The T4 to T3 dose ratio thus can vary substantially between participants within the same RCT (e.g. ranging from 20:1 to 4:1) [44]. Other studies replaced a proportion of the L-T4 dose by a variable L-T3 dose, resulting in a fixed ratio of administered $\mathrm{T} 4$ to $\mathrm{T} 3$
Table 3. Ratios of serum FT4 to FT3 concentrations (both in pmol/l) in L-T4-treated hypothyroid patients at baseline, and after completing study medication with either $\mathrm{T} 4$ or $\mathrm{T} 4+\mathrm{T} 3$

\begin{tabular}{lccc}
\hline Author & $\begin{array}{c}\text { Baseline T4 } \\
\text { monotherapy }\end{array}$ & $\begin{array}{c}\text { T4+T3 } \\
\text { combination }\end{array}$ \\
\hline Saravanan et al. [39] & 5.5 & 5.5 & 3.9 \\
Walsh et al. [41] & 4.5 & 4.2 & 3.3 \\
Sawka et al. [43] & 3.9 & 4.0 & 2.2 \\
Escobar-Morreale et al. [46] & 4.1 & 4.1 & 3.4 \\
Siegmund et al. [47] & 4.3 & 4.6 & 4.0 \\
\hline Mean FT4:FT3 ratio & 4.3 & 4.5 & 3.4 \\
\hline
\end{tabular}

dose for all participants within a trial (one study randomized patients to a fixed ratio of either 10:1 or 5:1) [40]. The variation in $\mathrm{T} 4$ to $\mathrm{T} 3$ dose ratio between studies aiming at a fixed ratio is large, ranging from 19:1 to 4:1. The wide variation in $\mathrm{T} 4$ to $\mathrm{T} 3$ dose ratio within and between RCTs constitutes a potential bias because most studies fail to mimic the ratio of $\mathrm{T} 4$ to $\mathrm{T} 3$ secretion by the human thyroid gland under physiological conditions, which is close to $13: 1$ by weight [1]. Nevertheless, combination therapy was judged not to be better than monotherapy in the four trials in the meta-analysis applying a fixed dose ratio of 19:1, $15: 1$ or $10: 1$ [38, 40,46, 47].

Along similar lines one may look at the ratio of serum free T4 to free T3. To obtain serum TSH values similar to controls during L-T4 monotherapy, serum free T4 concentrations higher than controls are required at serum free T3 values similar to those in controls [26, 27]. Indeed, serum free $\mathrm{T} 4$ to free $\mathrm{T} 3$ ratios in patients randomized to receive L-T4 monotherapy range from 4.0 to 5.5 (table 3), higher than the value of 3.3 observed in healthy controls [49]. The serum free T4 to free T3 ratio during combination therapy ranges from 2.2 to 4.0. In only two RCTs the ratios (3.3. and 3.4, respectively) were close to control values, but both studies still failed to demonstrate superiority of combination therapy over monotherapy.

The L-T3 dose administered during combination therapy varied between 5 and $25 \mu$ g daily, with the exception of the oldest study in which $40-60 \mu \mathrm{g}$ L-T3 was given [37]. The daily L-T3 dose was administered as a single dose in all trials except four, in which it was divided in two doses $[37,40,42,43]$.

\section{Duration of L-T4 and L-T4 + L-T3 Treatment}

Exposure to study medication varied between 15 and 52 weeks (median 16 weeks) in parallel studies, and between 5 and 12 weeks (median 8 weeks) in crossover studies. 
Table 4. Preference of patients in RCTs comparing T4 monotherapy with T4+T3 combination therapy in crossover or parallel study designs

\begin{tabular}{|c|c|c|c|c|c|}
\hline Author & $\mathrm{n}$ & $\begin{array}{l}\text { Preference T4 } \\
\text { monotherapy }\end{array}$ & $\begin{array}{l}\text { Preference } \\
\text { none }\end{array}$ & $\begin{array}{l}\text { Preference } \mathrm{T} 4+\mathrm{T} 3 \\
\text { therapy }\end{array}$ & $\mathrm{p}$ value \\
\hline \multicolumn{6}{|l|}{ Crossover studies } \\
\hline Walsh et al. [41] & 100 & 46 & 18 & 36 & 0.32 \\
\hline Nygaard et al. [5] & 59 & 9 & 21 & 29 & 0.002 \\
\hline Bunevicius et al. [44] & 33 & 2 & 11 & 20 & 0.001 \\
\hline Escobar-Morreale et al. [46] & 26 & 2 & 6 & $18^{*}$ & 0.015 \\
\hline Bunevicius et al. [48] & 10 & 2 & 2 & 6 & - \\
\hline Total & $228(100 \%)$ & $61(27 \%)$ & $58(25 \%)$ & $109(48 \%)$ & \\
\hline \multicolumn{6}{|l|}{ Parallel study } \\
\hline Appelhof et al. [40] & 140 & $14 / 48(29 \%)$ & & $43 / 92(47 \%)$ & 0.024 \\
\hline
\end{tabular}

\section{Final Serum TSH}

A few studies report adjustment of L-T3 dose in order to maintain serum TSH values within a certain range as specified in the study protocol. Serum TSH values at the end of combination therapy were higher than serum TSH values at the end of L-T4 monotherapy in two trials, similar in seven trials, and lower in two trials. Serum TSH was not determined in two trials. Suppressed serum TSH levels were observed in one study, at the end of combination therapy in an L-T4 to L-T3 dose ratio of $5: 1[40]$.

Outcome of RCT by Quality of Life (QoL), Cognition, Mood, Symptoms

There is some variation in the applied outcome instruments, but overall similarities in assessment between studies are rather high. Combination therapy was not better than L-T4 monotherapy in nine but better in three of the 12 RCTs. This outcome is not related to serum TSH values at the end of the study medication. One study demonstrated a significantly greater reduction in psychiatric caseness during combination therapy as compared to L-T4 monotherapy ( 19.2 vs. $26.6 \%$, odds ratio $0.61,95 \%$ CI $0.42-0.90)$ as well as an improvement in an anxiety score (OR 0.61, 95\% CI 0.32-0.95) at three months, but no differences were seen at 12 months [39]. The meta-analysis included the 3-month outcome of this study. The meta-analysis of all RCTs listed in table 2 (not incorporating [5] and [37]) concluded that L-T4 + L-T3 combination therapy used as replacement therapy for patients treated for hypothyroidism provided no advantage when compared with standard L-T4 monotherapy [34]. As mentioned above, it is unlikely the conclusion of the metaanalysis will change by incorporating the 2009 study [5]. In that study, depression scores and seven out of $11 \mathrm{QoL}$ scores were significantly better during combination therapy than during L-T4 monotherapy.

\section{Outcome of RCT according to Patients' Preference}

Patients were asked in seven of the 13 RCTs which study medication they preferred. We excluded one of these seven trials from further analysis in view of a high incidence of unpleasant symptoms during combination therapy (31 vs. 9\% during L-T4 monotherapy), undoubtedly caused by the very high daily doses of 40 and $60 \mu \mathrm{g}$ L-T3 in this study [37]. Preferences in the remaining six trials are listed in table 4 . Preferences are similar in studies with a crossover or parallel study design. L-T4 monotherapy is preferred by $28 \%$ of participants, although their L-T4 dose in the study period was exactly the same as prior to randomization. It points to a significant Hawthorne effect: benefit from improved routine care within a trial and from being investigated. Patients feel better just by participating in a trial. Whereas $52 \%$ of participants expressed no preference or a preference for L-T4 monotherapy, it is striking that $48 \%$ preferred L-T4 + L-T3 combination therapy. Patient preference for combination therapy was associated with improvement in QoL, cognition, mood and symptoms in three trials $[5,44,48]$ but absent in two trials $[40,46]$. Losing weight has been 
proposed as an explanation for patients' preference. Changes in body weight were $+0.1 \mathrm{~kg},-0.5 \mathrm{~kg}$ and $-1.7 \mathrm{~kg}$ in patients randomized to receive $\mathrm{L}-\mathrm{T} 4$ alone, $\mathrm{L}-\mathrm{T} 4+\mathrm{L}-\mathrm{T} 3$ in a ratio of 10:1, or L-T4 + L-T3 in a ratio of 5:1, respectively ( $\mathrm{p}=0.01$ for trend) [40]; the largest loss in body weight was obtained at the expense of a suppressed serum TSH (mean $0.07 \mathrm{mU} / 1$, range $0.02-1.05$ ). Mean changes in body weight during L-T4 or L-T4 + L-T3 therapy were +0.2 and $-1.5 \mathrm{~kg}$, respectively, in the study by Nygaard et al. [5] preferring combination therapy, and -0.1 and -0.2 $\mathrm{kg}$, respectively, in the study by Walsh et al. [41] with no preference. Three further studies assessed body weight, but none reported significant changes [39, 42, 45].

\section{Synopsis of RCTs}

There is marked heterogeneity among the reviewed RCTs, as evident from large differences in sample size, recruitment policy, cause of hypothyroidism, study design, T4 to T3 dose ratio, and duration of intervention. The wide variation in the administered $\mathrm{T} 4$ to $\mathrm{T} 3$ dose ratio within and between RCTs is of special concern, constituting a potential serious confounder. For, if one assumes persistent symptoms in L-T4-treated hypothyroid patients are due to higher than normal serum free T4 to free $\mathrm{T} 3$ ratios, the $\mathrm{T} 4$ to $\mathrm{T} 3$ dose ratio during combination therapy should mimic the physiological ratio of T4 to T3 secretion by the thyroid gland in order to secure normal serum free T4 to free T3 ratios: this is not accomplished in most trials.

The meta-analysis found combination therapy was not better than monotherapy by assessment of QoL, mood, symptoms and cognition [34]. Inclusion of the recent study by Nygaard et al. [5] is unlikely to change the outcome of the meta-analysis. The meta-analysis did not perform a quantitative analysis of patient's preference [34]. Our analysis (table 4) indicates about half of patients preferred combination therapy over monotherapy. The significance of this finding is limited by relevant data being available in only six trials and due to preference resulting from overtreatment with thyroid hormones in one trial [40].

\section{Recommendations}

(4) There is insufficient evidence that L-T4 + L-T3 combination therapy serves the hypothyroid patient better than T4 monotherapy $(1 /++0)$.

(5) It is recommended that $\mathrm{L}-\mathrm{T} 4$ monotherapy remains the standard treatment of hypothyroidism $(1 /+++)$.
Could It Be that Trials Comparing L-T4 + L-T3

Combination Therapy and L-T4 Monotherapy Have

Not Targeted the Right Population?

The effects of thyroid hormones in target tissues are determined by many factors beyond their serum levels, including local expression and activity of thyroid hormone transporters and deiodinases [51]. Polymorphisms in genes involved in thyroid hormone pathways may change the set-point of the hypothalamus-pituitary-thyroid axis, and such small but common genetic variations may also modulate the effect of exogenous T4 in particular target tissues of hypothyroid patients.

Phosphodiesterase $8 \mathrm{~B}$ gene (PDE8B) variants are associated with serum TSH (e.g. each additional copy of the minor allele of rs4704397 is associated with an increase of $0.13 \mathrm{mU} / \mathrm{l}$ in serum TSH [52]). The results suggest a primary effect of PDE8B variants in the thyroid, causing increased phosphodiesterase activity and hence a reduced ability of the thyroid gland to generate free T4 on TSH stimulation. Subsequent studies also reported the association between PDE8B and higher serum TSH, but not between PDE8B and serum free T4 which would have expected to be lower $[53,54]$. A recent meta-analysis confirmed that genetic variation in PDE8B is associated with serum TSH (+0.20 SD/allele), and identified a possible new association with free T4 (-0.07 SD/allele) [55]. The association is lost in subjects on thyroid hormone replacement. This observation emphasizes that although thyroid hormone replacement may return an individual's serum TSH levels to within the reference range, this may be outside an individual's genetically determined set-point [55]. A meta-analysis of 1,512 studied polymorphisms in 68 thyroid hormone pathway genes in four populations showed a significant association of 30 SNPs in 10 genes with TSH; only 8 SNPs in PDE8B remained significant with $\mathrm{p}$ values below the threshold of 0.0022 [54].

The DIO1 gene encodes the iodothyronine deiodinase type 1 (D1), present in liver, kidney and thyroid. D1 plays a key role in the production of T3 from T4 and in the clearance of rT3. Polymorphisms in DIO1 are associated with serum FT4 but not with serum TSH [56-58]. The findings have been replicated in two recent large studies (with p values below the threshold of 0.0033 ) $[54,55]$. The C-allele of SNP rs2235544 in DIO1 is associated with increased D1 activity with resulting increase in serum free $\mathrm{T} 3$, decrease in serum free T4 and reverse T3 (rT3), and thereby in a decreased serum free T4 to free T3 concentration ratio. This is also observed in hypothyroid patients on L-T4 replacement (table 5) [57]. However, SNPs 
Table 5. Relation between polymorphism rs2235544 in DIO1 and thyroid function in hypothyroid patients on L-T4 replacement (derived from Panicker et al. [57], with modifications)

\begin{tabular}{lcccl}
\hline Genotype & AA & AC & CC & $\begin{array}{l}\text { p value } \\
\text { for trend }\end{array}$ \\
\hline FT4, pmol/l & 21.7 & 21.1 & 20.4 & 0.007 \\
FT3, pmol/l & 3.75 & 3.88 & 3.91 & 0.092 \\
FT4/FT3 ratio & 5.79 & 5.44 & 5.22 & 0.001 \\
TSH, mU/l & 0.79 & 0.65 & 0.67 & NS \\
\hline
\end{tabular}

in DIO1 are not related to psychological well-being or response to L-T4 + L-T3 combination therapy [59].

Polymorphisms in $\mathrm{DIO} 2$ and $\mathrm{DIO} 3$ are not associated with serum TSH or thyroid hormone concentrations according to the most recent and largest studies [54, 55, 57]. Thus, the early observation that particular polymorphisms in $\mathrm{DIO} 2$ were dose-dependently associated with free T4 and rT3 [60] could not be replicated. One of these variants (Thr92Ala) was thought to be associated with decreased D2 activity. Indeed, the need for a higher L-T4 dose to obtain target serum TSH levels in thyroidectomised patients was higher in carriers of this SNP [61]. These results were not confirmed in another study reporting no association between D2 Thr92Ala and serum thyroid hormone levels or L-T4 dosage in patients with thyroid cancer or Hashimoto's thyroiditis [62]. D2 catalyses the conversion of T4 into T3, and is especially important in the local control of thyroid hormone signal-ling [63]. Animal studies suggest that up to $80 \%$ of intracellular T3 in the brain is derived from circulating T4 by local deiodination into T3 via D2. Thus, D2 polymorphisms may affect $\mathrm{T} 3$ content in the brain without evident changes in circulating thyroid hormones. Two SNPs in DIO2 including Thr92Ala were not associated with well-being, neurocognitive functioning, and preference for combined L-T4 + L-T3 therapy [64]. These negative results are possibly due to the still limited sample size of 141 patients in this study, because a larger study among 552 patients on L-T4 replacement reported positive results [59]. The rarer phenotype rs225014 of DIO2 was present in 16\% of the subjects on L-T4 therapy, and associated with worse scores on the General Health Questionnaire (GHQ) (scores 14.1 vs. $12.8, \mathrm{p}=0.03)$. This genotype showed greater improvement on L-T4 + L-T3 combination therapy compared with L-T4 monotherapy, by 2.3 GHQ points at 3 months and 1.4 at 12 months ( $p=0.03$ for repeated measures ANOVA). The results require replication but suggest that $\mathrm{DIO} 2$ poly- morphisms are associated with impaired psychological well-being in patients on L-T4 replacement and enhanced response to L-T4 + L-T3 combination therapy.

A large number of SNPs in other genes involved in thyroid hormone pathways (including sulfatases and thyroid hormone transporters) have been investigated, but none was associated with serum TSH or free T4 [54]. One study shows an influence of SNPs in the brain-specific thyroid hormone transporter OATP1C1 in hypothyroid patients on L-T4 [65]. Both the OATP1C1-intron 3C $>\mathrm{T}$ and the OATP1C1-C3035T polymorphisms (but not the OATP1C1-Pro143Thr polymorphism) were associated with symptoms of fatigue and depression. OATP1C1 polymorphisms were not associated with measures of neurocognitive functioning or preference for $\mathrm{T} 4+\mathrm{T} 3$ combination therapy.

\section{Recommendations}

(6) Limited data suggest that psychological well-being and preference for L-T4 + L-T3 combination therapy may be influenced by polymorphisms in thyroid hormone pathway genes, specifically in thyroid hormone transporters and deiodinases $(2 /+00)$.

\section{Which Patients Would Qualify for L-T4 + L-T3 Combination Therapy}

Table 1 lists a number of possibilities to explain persistent complaints in L-T4-treated hypothyroid patients, assuming serum TSH concentrations have been normalized to within the reference range and patients are compliant with the prescribed medication. It seems reasonable that under these circumstances health care providers first give support to the patient by reassuring the patient on the overall satisfactory outcome of hypothyroidism with thyroid hormone replacement, and by discussing any difficulties perceived by the patient who is confronted with the chronic nature of the disease and the usual need for lifelong medication. The presence of any autoimmune disease associated with thyroid autoimmunity requires exclusion. If after an arbitrary period of about six months the persisting symptoms have not improved, L-T4 + L-T3 combination therapy might be considered. It is not known if general and disease-specific health-related questionnaire scores can be helpful in the decision to consider L-T4 + L-T3 combination therapy.

The patient should be informed on the experimental nature of L-T4 + L-T3 combination therapy. It means that if the experiment fails (persistent symptoms do not im- 
prove), the L-T4 + L-T3 combination therapy should be discontinued and L-T4 monotherapy reinstituted. The duration of the L-T4 + L-T3 combination trial should be limited to a period that has been fixed and agreed with the patient before starting. A period of 3 months for the trial seems reasonable in view of the finding that any improvement upon L-T4 + L-T3 combination treatment in the randomized clinical trials was observed in this time frame. If L-T4 + L-T3 combination therapy is effective and well tolerated, it may be continued beyond the trial period. A positive outcome at 3 months might be caused by a placebo effect, and it may not be uncommon that the positive outcome is not sustained with longer duration of L-T4 + L-T3 combination treatment.

Whereas during L-T4 monotherapy no change in serum free T3 is seen in the first four hours post-dose, during L-T4 + L-T3 combination therapy a marked rise of $42 \%$ in serum free $\mathrm{T} 3$ has been observed within the first $4 \mathrm{~h}$ after ingestion of L-T3 [66]. The increase of serum free T3 may provoke cardiac arrhythmias in susceptible patients. There is insufficient data on fetal consequences of L-T4 + L-T3 combination therapy in pregnant women. Consequently, it seems prudent for safety reasons to refrain from L-T4 + L-T3 combination therapy in pregnant women and in patients with cardiac arrhythmias.

\section{Recommendations}

(7) It is suggested that L-T4 + L-T3 combination therapy might be considered as an experimental approach in compliant L-T4-treated hypothyroid patients who have persistent complaints despite serum TSH values within the reference range, provided they have previously given support to deal with the chronic nature of their disease and associated autoimmune diseases have been ruled out $(2 /+00)$.

(8) $\mathrm{T} 4+\mathrm{T} 3$ combination therapy is not recommended in pregnant women and in patients with cardiac arrhythmias $(2 /+00)$.

(9) It is suggested that L-T4 + L-T3 combination therapy is discontinued if no improvement is experienced after 3 months $(2 /++0)$.

\section{What Is the Appropriate Dosage of L-T4 + L-T3} Combination Therapy?

The goal of L-T4 + L-T3 combination therapy is to resolve persistent complaints despite a normal TSH in L-T4-treated hypothyroid patients. In an attempt to realize this goal, it is assumed that:
- persistent complaints in this context are related to findings in rats that $\mathrm{T} 4$ monotherapy does not ensure euthyroidism simultaneously in all tissues [32];

- a euthyroid state simultaneously in all tissues of hypothyroid patients can be reached by L-T4 + L-T3 in a dose ratio that mimics the physiological $\mathrm{T} 4$ to $\mathrm{T} 3 \mathrm{se}$ cretion ratio by the human thyroid gland [33];

- a euthyroid state simultaneously in all tissues of hypothyroid patients is present if serum TSH, free T4, free $\mathrm{T} 3$ and free T4:free $\mathrm{T} 3$ ratio are all within the reference range.

None of these assumptions may of course be true, underlining the experimental nature of L-T4 + L-T3 combination therapy. Based on these premises, however, suggestions can be made for the most appropriate dose of L-T4 and L-T3 when choosing combination therapy.

A recent large study in 1,811 athyreotic patients with normal serum TSH levels under L-T4 monotherapy and 3,875 euthyroid controls confirmed higher free T4 to free T3 serum concentration ratios in L-T4-treated hypothyroid patients compared to controls (4.16 vs. 3.09, p < 0.001) [67]. In the L-T4-treated patients, despite a serum TSH value within the normal range of $0.4-4.0 \mathrm{mU} / 1,7.2 \%$ had serum free T4 levels above the upper normal limit, $15.2 \%$ had serum free T3 levels below the lower normal limit, and $29.6 \%$ had free T4/free T3 ratios higher than the normal range. The percentage of patients with an abnormally high free T4/free T3 ratio increased with increasing L-T4 dose $(24.4,31.1$ and $37.7 \%$ in patients treated with a L-T4 dose of $<1.50,1.51-2.00$ and $>2.00 \mu \mathrm{g} / \mathrm{kg} /$ day, respectively). Subdividing participants according to their serum TSH, serum free T4 was higher and serum free T3 was lower in each TSH stratum in L-T4-treated patients than in TSH-matched euthyroid controls. Whereas the familiar negative log-linear relationship between serum TSH and free T4 was observed in both groups, the linear regression line in L-T4-treated patients was much steeper than in controls: thus, a greater change in serum free T4 is required in L-T4-treated patients in order to obtain the same feedback on pituitary TSH secretion [67]. The slope of the negative log-linear relationship between serum TSH and free T3 is also much steeper in L-T4-treated patients than in controls: smaller T3 changes are associated with wider serum TSH changes $[67,68]$. These differences may be related to differences in serum T3 and free T3 concentrations, which are lower in L-T4-treated patients than in controls (T3 1.60 vs. 1.86 $\mathrm{nmol} / \mathrm{l}$, free T3 3.70 vs. $4.47 \mathrm{pmol} / \mathrm{l}, \mathrm{p}<0.001)[67,68]$. It appears that some patients are unable to convert the ingested L-T4 into an adequate amount of T3 [67]. The in- 
sufficient peripheral $\mathrm{T} 3$ production cannot be appropriately corrected by increasing L-T4 dose, because the inhibitory effect of elevated T4 on D2 [28, 30, 69] will end up increasing the imbalance of serum free $\mathrm{T} 4$ to free $\mathrm{T} 3$ ratio [67]. Tissues differ in their regulation of intracellular T3 available for binding to nuclear T3 receptors, which can be derived from plasma T3 or can be produced locally from T4. Because of tissue heterogeneity, pituitary TSH secretion may not reflect what happens in other target tissues, and therefore serum TSH alone may not be a good marker for the adequacy of thyroid hormone replacement $[67,68,70]$. Theoretically, thyroid hormone replacement therapy should aim not only at normalization of serum TSH but also at normalization of serum free T4, free $\mathrm{T} 3$ and free $\mathrm{T} 4 /$ free $\mathrm{T} 3$ ratio.

The pharmacodynamic equivalence of L-T4 and L-T3 has been recently studied in a randomized, double-blind, cross-over study in 10 thyroidectomized patients [71]. The target (TSH $\geq 0.5 \leq 1.5 \mathrm{mU} / \mathrm{l}$ for at least 30 days) was reached by an average daily dose of $40.3 \pm 11.3 \mu \mathrm{g} \mathrm{L}-\mathrm{T} 3$ and $115.2 \pm 38.5 \mu \mathrm{g} \mathrm{L}-\mathrm{T} 4$ (L-T3:L-T4 ratio $0.36 \pm 0.06$ ). It was concluded that therapeutic substitution of L-T3 for L-T4 was achieved at approximately 1:3 ratio. To some extent these data can be used to calculate the dose of L-T4 and L-T3 in L-T4 + L-T3 combination therapy as follows (table 6, method A):

A1: Daily L-T4 dose in $\mu g$ that has normalized serum TSH during L-T4 monotherapy is called dose $\mathrm{x}$.

A2: Daily L-T3 dose in $\mu \mathrm{g}$ is called dose $\mathrm{y}$, calculated as $\mathrm{x}: 17$ (to approach the physiological T4:T3 thyroidal secretion rate of $16: 1$, out of any given L-T4 dose $\mathrm{x}$ sixteen parts should be allocated to L-T4 and one part to L-T3 when considering to switch to combination therapy; therefore, the L-T4 dose $\mathrm{x}$ is divided by 17 in the calculation of the L-T3 dose y) [1].

A3: Daily L-T4 dose in $\mu \mathrm{g}$ is called dose $\mathrm{z}$, calculated as $\mathrm{x}-3 \mathrm{y}$ (to adjust for the pharmacodynamic equivalence ratio of 1:3 for L-T3 and L-T4) [71]. From the examples given in table 6 , it can be seen that the calculated L-T4/LT3 dose ratio for method $\mathrm{A}$ is 14:1, and 13:1 to 14:1 after rounding off dosages to the nearest available strength.

An alternative method takes into account differences in gastrointestinal absorption of thyroid hormones. It has been reported that $65-75 \%$ of oral L-T4 and $69-99 \%$ of oral L-T3 is absorbed [72-75]. Assuming $80 \%$ absorption of L-T4 and $100 \%$ absorption of L-T3 the dose of L-T4 and $\mathrm{L}-\mathrm{T} 3$ in L-T4 + L-T3 combination therapy is calculated as follows (table 6, method B1):

B1: Daily L-T4 dose in $\mu \mathrm{g}$ that has normalized serum TSH during T4 monotherapy is called dose $\mathrm{x}$.
Table 6. Methods for calculating L-T4 and L-T3 dosages for T4+T3 combination therapy

\begin{tabular}{|c|c|c|c|}
\hline T4 monotherapy & $\begin{array}{l}100 \mu \mathrm{g} \\
\mathrm{L}-\mathrm{T} 4= \\
\text { dose } \mathrm{x}\end{array}$ & $\begin{array}{l}150 \mu \mathrm{g} \\
\mathrm{L}-\mathrm{T} 4= \\
\text { dose } \mathrm{x}\end{array}$ & $\begin{array}{l}200 \mu g \\
\mathrm{~L}-\mathrm{T} 4= \\
\text { dose } \mathrm{x}\end{array}$ \\
\hline \multicolumn{4}{|c|}{$T 4+T 3$ combination, method $A, \mu g$} \\
\hline L-T3 dose y $(y=x: 17)$ & 5.88 & 8.82 & 11.76 \\
\hline L-T4 dose $z(z=x-3 y)$ & 82.36 & 123.54 & 164.71 \\
\hline L-T3 dose (round off) & 6.25 & 9.37 & 12.5 \\
\hline L-T4 dose (round off) & 87.5 & 125 & 162.5 \\
\hline L-T4:L-T3 dose ratio & $14: 1$ & $13: 1$ & $13: 1$ \\
\hline \multicolumn{4}{|c|}{ T4+T3 combination, method B1, $\mu \mathrm{g}$} \\
\hline L-T3 dose y $(y=0.8 x: 17)$ & 4.70 & 7.05 & 9.41 \\
\hline $\mathrm{L}-\mathrm{T} 4$ dose $\mathrm{z}(\mathrm{z}=16 \mathrm{y} \times 1.25)$ & 94.12 & 141.18 & 188.24 \\
\hline L-T3 dose (round off) & 6.25 & 6.25 & 9.37 \\
\hline L-T4 dose (round off) & 87.5 & 125 & 187.5 \\
\hline L-T4:L-T3 dose ratio & $14: 1$ & $20: 1$ & $20: 1$ \\
\hline \multicolumn{4}{|c|}{ T4+T3 combination, method B2, $\mu \mathrm{g}$} \\
\hline L-T3 dose y $(y=0.7 x: 17)$ & 4.12 & 6.18 & 8.24 \\
\hline L-T4 dose $z(z=16 y \times 1.43)$ & 94.21 & 141.31 & 188.42 \\
\hline L-T3 dose (round off) & 6.25 & 6.25 & 9.37 \\
\hline L-T4 dose (round off) & 87.5 & 125 & 187.5 \\
\hline L-T4:L-T3 dose ratio & $14: 1$ & $20: 1$ & $20: 1$ \\
\hline \multicolumn{4}{|c|}{ T4+T3 combination, method $C, \mu g$} \\
\hline L-T3 dose y $(y=x: 20)$ & 5 & 7.5 & 10 \\
\hline L-T4 dose $z(z=x-3 y)$ & 85 & 127.5 & 170 \\
\hline L-T4 dose (round off) & 87.5 & 125 & 175 \\
\hline L-T4:L-T3 dose ratio & $17: 1$ & $17: 1$ & $17: 1$ \\
\hline
\end{tabular}

Dose $\mathrm{x}=$ Daily L-T4 dose in $\mu \mathrm{g}$ that has normalized serum TSH during T4 monotherapy.

B2: Daily L-T4 dose that has been absorbed and produced normal TSH is $0.8 \mathrm{x}$ (assuming $80 \%$ absorption of L-T4) [72-75].

B3: Daily L-T3 dose in $\mu \mathrm{g}$ is called dose y, calculated as $0.8 \mathrm{x}: 17$ (to approach the physiological T4:T3 thyroidal secretion ratio of 16:1) [1].

B4: Daily L-T4 dose in $\mu \mathrm{g}$ is called dose $\mathrm{z}$, calculated as $16 y$ times 1.25 (to approach the physiological T4:T3 thyroidal secretion ratio of $16: 1$ in combination therapy, the L-T4 dose $\mathrm{z}$ should be 16 times the L-T3 dose $\mathrm{y}$; the multiplication factor 1.25 is used to adjust for $80 \%$ absorption of L-T4 and 100\% absorption of L-T3) [72-75]. The L-T4/LT3 dose ratio calculated with method B1 is $16: 1$ before correction for absorption and 14:1 to 20:1 after rounding off to the nearest strength available. Assuming 70\% absorption of oral L-T4 does not significantly change the final dose of L-T3 and L-T4 (table 6, method B2). 
Method C is the simplest protocol, although it does depend on the availability of L-T3 strength.

C1: Daily L-T4 dose in $\mu g$ that has normalized serum TSH during T4 monotherapy is called dose $\mathrm{x}$.

C2: Daily L-T3 dose in $\mu$ g is called dose y, calculated as $\mathrm{x}: 20$.

C3: Daily L-T4 dose in $\mu \mathrm{g}$ is called dose $\mathrm{z}$, calculated as $\mathrm{x}-3 \mathrm{y}$. The L-T4/L-T3 dose ratio calculated with method $\mathrm{C}$ is rather stable, around 17:1 (table 6, method C).

It is difficult to predict which method will be preferable. What is clear, however, is that the suggested L-T4/LT3 dose ratio is higher than the ratios applied in most RCTs (table 2). In order to avoid a substantial rise of serum FT3 in the absorption phase of L-T3 [66, 76], it might be prudent to split the daily L-T3 dose in two doses, if possible. Whereas serum free T4 remains constant over $24 \mathrm{~h}$, there is a circadian free T3 rhythm with its acrophase occurring around 3 a.m., approximately $90 \mathrm{~min}$ after TSH acrophase [77]. In order to mimic the circadian free T3 rhythm, the larger of the two daily doses of L-T3 might be given at bedtime.

\section{Recommendations}

(10) It is suggested that L-T4 + L-T3 combination treatment should be started in a L-T4/L-T3 dose ratio between 13:1 and $20: 1$ by weight $(2 /+00)$.

(11) Whereas L-T4 can be given once daily, the daily L-T3 dose should be divided (if possible) in two doses (one before breakfast and the largest one before sleeping) $(2 /+00)$.

\section{Which Preparations Can Be Used in L-T4 + L-T3}

Combination Therapy and How Should Their Use Be Monitored?

Levothyroxine (L-T4) tablets are widely available, produced by a number of pharmaceutical companies in strengths ranging from 25 to $200 \mu \mathrm{g}$. Liothyronine (L-T3) tablets are commercially produced (brand names, e.g. Cytomel in strengths of $5 \mu \mathrm{g}, 12.5 \mu \mathrm{g}$ and $25 \mu \mathrm{g}$; Thybon in strengths of $20 \mu \mathrm{g}$ and $100 \mu \mathrm{g}$ ); their availability varies per country. L-T4 + L-T3 combination tablets are also commercially available. The L-T4/L-T3 dose ratio in combination tablets is lower than the recommended ratio of $13: 1$ to $20: 1$, and may be variable from batch to batch. For example, Armour Thyroid (a mixture of T4 and T3, made from porcine thyroid glands) contains about $38 \mu \mathrm{g}$ L-T4 and $9 \mu \mathrm{g} \mathrm{L}-\mathrm{T} 3$ per one grain $(60 \mathrm{mg}$ of desiccated thyroid extract), that is a L-T4/L-T3 dose ratio of 4.2:1.
Dose ratios of other combination tablets are 10:1 (Prothyrid, $100+10), 5: 1$ (Novothyral, $100+20,75+15,25+5)$ and 4:1 (Thyreotom, $120+30,40+10 \mu \mathrm{g} \mathrm{L-T4}+\mu \mathrm{g}$ L-T3, respectively). All these combination tablets (including those containing animal thyroid extract) are potentially harmful as due to their relatively high T3 content they carry a risk of inducing symptoms of thyroid hormone excess. It is therefore recommended to use separate L-T4 and L-T3 tablets in L-T4 + L-T3 combination therapy. One may prefer to use brand names for L-T3 replacement in order to avoid errors in manufacturing L-T3 tablets of just a few micrograms by the local pharmacy. The 12.5$\mu \mathrm{g}$ Cytomel tablets can be divided in smaller parts of $3.125 \mu \mathrm{g}$ each.

Monitoring of L-T4 + L-T3 combination therapy should be done by thyroid function tests in blood samples withdrawn before morning medication has been taken. In doing so, one avoids the risk of measuring relatively high free T3 levels in the absorption phase of thyroid hormone replacement [66]. One should aim at normalization of serum TSH, free T4, free T3 and free T4/free T3 ratio. Because there is substantial variation between free $\mathrm{T} 4$ and free T3 assays, each laboratory should endeavour to establish its own reference ranges. It seems reasonable to check thyroid function tests about 6-8 weeks after starting L-T4 + L-T3 combination therapy, as it is likely that a new equilibrium has been established at that time. Abnormal test results would qualify for dose adjustment. It is suggested to change the dose of just one of the components of the combination therapy. If serum free T3 is too low, an increase of L-T3 dose is logical, as a higher L-T4 dose is likely to increase serum free T4. If serum free T4 is too high, an increase of L-T3 dose will lower serum free T4. Therefore in many instances adjustment of the L-T3 dose will be indicated. The experimental nature of L-T4 + L-T3 combination therapy, the complexity around finding the appropriate L-T4 and L-T3 dosages, and the need for close monitoring of the instituted treatment suggest that L-T4 + L-T3 combination therapy should be reserved for use by accredited specialists in the field of internal medicine/endocrinology.

\section{Recommendations}

(12) As the currently available L-T4 + L-T3 combination preparations contain a L-T4/L-T3 dose ratio lower than $13: 1$, it is recommended to use separate L-T4 and $\mathrm{L}-\mathrm{T} 3$ tablets in L-T4 + L-T3 combination therapy $(1 /+00)$.

(13) It is recommended that L-T4 + L-T3 combination therapy should be monitored by thyroid function tests in blood samples withdrawn before morning medication 
has been taken, aiming at normal serum TSH, free T4, free $\mathrm{T} 3$ and free $\mathrm{T} 4 /$ free $\mathrm{T} 3$ ratio $(1 /++0)$.

(14) If dose adjustment of L-T4 + L-T3 combination therapy is necessary to achieve a normal serum TSH, free $\mathrm{T} 4$, free $\mathrm{T} 3$ and free T4/free T3 ratio, it is suggested the dose of just one of the components is changed, preferably of L-T3 $(2 /+00)$.

(15) It is suggested that treatment of hypothyroidism by the combination of L-T4 and L-T3 should be supervised by accredited internists/endocrinologists $(2 /++0)$.

\section{What Are Areas for Future Research on This Topic?}

There is an urgent need for further research in order to understand the nature of persisting symptoms in patients on T4 monotherapy despite a serum TSH within the reference range. The nature of such persisting symptoms could be evaluated in a prospective study in hypothyroid patients starting L-T4 monotherapy. Putative determinants could be assessed by comparing baseline characteristics of patients who will be satisfied and who will not be satisfied with the outcome of L-T4 monotherapy once serum TSH has been normalized. Other studies may investigate more precisely the L-T4/L-T3 dose ratio that best approximates the serum free T4/free T3 concentration ratios in healthy subjects. Randomized clinical trials comparing L-T4 + L-T3 combination therapy and L-T4 monotherapy may be performed in hypothyroid patients who are carriers of polymorphisms in thyroid hormone transporters and deiodinases to test the hypothesis that the outcome of combination therapy is better than that of L-T4 monotherapy in this subset of patients. The introduction of a slow-release preparation of L-T3 might be very useful. A slowrelease formula of L-T3 may prevent the marked rise of free T3 after ingestion of the current L-T3 tablets. Proof of principle of such preparations has been obtained in a recent study, in which the serum free $\mathrm{T} 4 /$ free $\mathrm{T} 3$ ratio was lower during L-T4 + slow-release L-T3 therapy than during L-T4 monotherapy, although still higher than in controls [76]. Finally, the long-term efficacy and safety of L-T4 $+\mathrm{L}-\mathrm{T} 3$ combination therapy should be assessed. The consequences, if any, of prolonged L-T4 + L-T3 combination therapy for bone and cardiovascular health are unknown [50]. Likewise, the safety of L-T4 + L-T3 combination therapy is unclear in patients with cardiovascular diseases other than cardiac arrhythmias.

\section{Recommendations}

(16) Suggestions for future research are:

(a) prospective studies in hypothyroid patients starting L-T4 therapy, comparing baseline characteristics between those who will and those who will not be satisfied with the outcome of L-T4 monotherapy;

(b) trials investigating the L-T4/L-T3 dose ratio that best approximates the serum FT4/FT3 concentration ratios in healthy subjects;

(c) randomized clinical trials comparing L-T4 + L-T3 combination therapy and L-T4 monotherapy in hypothyroid patients who are carriers of polymorphisms in thyroid hormone transporters and deiodinases;

(d) studies with a slow-release preparation of L-T3;

(e) prospective studies assessing the long-term efficacy and safety of L-T4 + L-T3 combination therapy $(2 /+00)$.

\section{Disclosure Statement}

W.M. Wiersinga received fees from Genzyme as an Advisory Board member. The other members of the task force had nothing to disclose.

\section{References}

$>1$ Pilo A, Iervasi G, Vitek F, Ferdeghini M, Cazzuola F, Bianchi R: Thyroidal and peripheral production of 3,5,3'-triiodothyronine in humans by multicompartmental analysis. Am J Physiol 1990;258:E715-E726.

$\checkmark 2$ Singer PA, Cooper DS, Levy EG, Ladenson PW, Braverman LE, Daniels G, Greenspan FS, McDougall IR, Nikolai TF: Treatment guidelines for patients with hyperthyroidism and hypothyroidism. JAMA 1995;273:808-812.

3 Baskin HJ, Cobin RH, Duick DS, Gharib H, Guttler RB, Kaplan MM, Segal RL: American Association of Clinical Endocrinologists medical guidelines for clinical practice for the evaluation and treatment of hyperthyroidism and hypothyroidism. Endocr Pract 2002;6:457-469.
4 www.hypomaarniethappy.nl

5 Nygaard B, Jensen EW, Kvetny J, Jarlov A, Faber J: Effect of combination therapy with thyroxine (T4) and 3,5,3'-triiodothyronine (T3) versus T4 monotherapy in patients with hypothyroidism, a double-blind, randomized cross-over study. Eur J Endocrinol 2009; 161:895-902.

6 Bahn RS, Burch HB, Cooper DS, Garber JR, Greenlee MC, Klein I, Laurberg P, McDougall IR, Montori VM, Rivkees SA, Ross DS, Sosa JA, Stan MN: Hyperthyroidism and other causes of thyrotoxicosis: management guidelines of the American Thyroid Association and American Association of Clinical Endocrinologists. Thyroid 2011;21:593-646.
7 Guyatt G, Gutterman D, Baumann MH, Addrizzo-Harris D, Hylek EM, Phillips B, Raskob G, Lewis SZ, Schunemann H: Grading strength of recommendations and quality of evidence in clinical guidelines. Report from an American College of Chest Physicians Task Force. Chest 2006;129: 174-181.

8 Swiglo BA, Murad MH, Schunemann HJ, Kunz R, Vigersky RA, Guyatt GH, Montori VM: A case for clarity, consistency, and helpfulness: state-of-the-art clinical practice guidelines in endocrinology using the grading of recommendations, assessment, development, and evaluation system. J Clin Endocrinol Metab 2008;93:666-673. 
9 Ladenson PW: Psychological wellbeing in patients. Clin Endocrinol 2002;57:575-576.

10 Weetman AP: Whose thyroid hormone replacement is it anyway? Clin Endocrinol 2006;64:231-233.

-11 Saravanan P, Chau W-F, Roberts N, Vedhara K, Greenwood R, Dayan CM: Psychological well-being in patients on 'adequate' doses of L-thyroxine: results of a large, controlled community-based questionnaire study. Clin Endocrinol 2002;57:577-585.

-12 Saravanan P, Visser TJ, Dayan CM: Psychological well-being correlates with free thyroxine but not free 3,5,3'-triiodothyronine levels in patients on thyroid hormone replacement. J Clin Endocrinol Metab 2006; 91:3389-3393.

$\checkmark 13$ Wekking EM, Appelhof BC, Fliers E, Schene AH, Huyser J, Tijssen JGP, Wiersinga WM: Cognitive functioning and well-being in euthyroid patients on thyroxine replacement therapy for primary hypothyroidism. Eur J Endocrinol 2005;153:747-753.

14 Panicker V, Evans J, Bjoro T, Asvold BO, Dayan CM, Bjerkeset O: A paradoxical difference in relationship between anxiety, depression and thyroid function in subjects on and not on T4: findings from the HUNT study. Clin Endocrinol 2009;71:574-580.

15 Petersen K, Bengtsson C, Lapidus L, Lindstedt G, Nystrom E: Morbidity, mortality, and quality of life for patients treated with levothyroxine. Arch Intern Med 1990;150: 2077-2081.

16 Samuels MH, Schuff KG, Carlson NE, Carello P, Janowsky JS: Health status, psychological symptoms, mood, and cognition in Lthyroxine treated hypothyroid subjects. Thyroid 2007; 17:249-258.

17 Canaris GJ, Manowitz NR, Mayor G, Ridgway EC: The Colorado Thyroid Disease Prevalence study. Arch Intern Med 2000; 160:526-534.

18 Wartofsky L: Combined levotriiodothyronine and levothyroxine therapy for hypothyroidism: are we a step closer to the magic formula? Thyroid 2004;14:247-248.

$\checkmark 19$ Cooper DS: Thyroxine monotherapy after thyroidectomy. Coming full circle. JAMA 2008;299:817-819.

20 Somers EC, Thomas SL, Smeeth L, Hall AJ: Are individuals with an autoimmune disease at higher risk of a second autoimmune disorder? Am J Epidemiol 2009;169:749-755.

$\checkmark 21$ Weetman AP: Diseases associated with thyroid autoimmunity: explanations for the expanding spectrum. Clin Endocrinol 2011;74: 411-418.

-22 Boelaert K, Newby PR, Simmonds MJ, Holder RL, Carr-Smith JD, Heward JM, Manji N, Allahabadia A, Armitage M, Chatterjee KV, Lazarus JH, Pearce SH, Vaidya B, Gough SC, Franklyn JA: Prevalence and relative risk of other autoimmune diseases in subjects with autoimmune thyroid disease. Am J Med 2010;123:183.e1-183.e9.

23 Engum A, Bjoro T, Mykletun A, Dahl AA: Thyroid autoimmunity, depression and anxiety; are there any connections? An epidemiological study of a large population. J Psychosom Res 2005;59:263-268.
24 Pop VJ, Maartens LH, Leusink G, van Son MJ, Knottnerus AA, Ward AM, Metcalfe R, Weetman AP: Are autoimmune thyroid dysfunction and depression related? J Clin Endocrinol Metab 1998;83:3194-3197.

25 Ott J, Promberger R, Kober F, Neuhold N, Tea M, Huber JC, Hermann M: Hashimoto's thyroiditis affects symptom load and quality of life unrelated to hypothyroidism: a prospective case-control study in women undergoing thyroidectomy for benign goiter. Thyroid 2011;21:161-167.

26 Fish LH, Schwartz HL, Cavanaugh J, Steffes MW, Bantle JP, Oppenheimer JH: Replacement dose, metabolism, and bioavailability of levothyroxine in the treatment of hypothyroidism: role of triiodothyronine in pituitary feedback in humans. N Engl J Med 1987;316:764-770.

27 Jonklaas J, Davidson B, Bhagat S, Soldin SJ: Triiodothyronine levels in athyreotic individuals during levothyroxine therapy. JAMA 2008;299:769-777.

28 Carr D, McLeod DT, Parry G, Thornes HM: Fine adjustment of thyroxine replacement dosage: comparison of the thyrotrophin releasing hormone test using a sensitive thyrotrophin assay with measurement of free thyroid hormones and clinical assessment. Clin Endocrinol 1988;28:325-333.

29 Walsh JP, Ward LC, Burke V, Bhagat CI, Shiels L, Henley D, Gillett MJ, Gilbert R, Tanner M, Stuckey BGA: Small changes in thyroxine dosage do not produce measurable changes in hypothyroid symptoms, well-being, or quality of life: results of a doubleblind, randomized clinical trial. J Clin Endocrinol Metab 2006;91:2624-2630.

30 Bianco AC, Kim BW: Deiodinase: implications of the local control of thyroid hormone action. J Clin Invest 2006;116:2571-2579.

31 Doorn J van, Heide D van der, Roelfsema F: The contribution of local thyroxine monodeiodination to intracellular 3,5,3'-triiodothyronine in several tissues of hypothyroid rats at isotopic equilibrium. Acta Endocrinol 1982;101:386-396.

32 Escobar-Morreale HF, Obregon MJ, Escobar del Rey F, Morreale de Escobar G: Replacement therapy for hypothyroidism with thyroxine alone does not ensure euthyroidism in all tissues, as studied in thyroidectomized rats. Endocrinology 1995;28:2828-2838.

- 33 Escobar-Morreale HF, Escobar del Rey F, Obregon MJ, Morreale de Escobar G: Only the combined treatment with thyroxine and triiodothyronine ensures euthyroidism in all tissues of the thyroidectomised rat. Endocrinology 1996;137:2490-2502.

34 Grozinsky-Glasberg S, Fraser A, Nahshoni E, Weizman A, Leibovici L: Thyroxine-triiodothyronine combination therapy versus thyroxine monotherapy for clinical hypothyroidism: meta-analysis of randomized controlled trials. J Clin Endocrinol Metab 2006;91:2592-2599.

35 Ma C, Xie J, Huang X, Wang G, Wang Y, Wang X, Zuo S: Thyroxine alone or thyroxine plus triiodothyronine replacement therapy for hypothyroidism. Nucl Med Commun 2009;30:586-593.
6 Wiersinga WM: Do we need still more trials on T4 and T3 combination therapy in hypothyroidism? Eur J Endocrinol 2009;161:955959.

37 Smith RN, Taylor SA, Massey JC: Controlled clinical trial of combined triiodothyronine and thyroxine in the treatment of hypothyroidism. Br Med J 1970;iv:145-148.

38 Levitt JA, Silverberg J: T4 plus T3 for hypothyroidism: a double-blind comparison with usual T4. Abstract, Proc 74th Ann Meet American Thyroid Association, Los Angeles, 2002.

-39 Saravanan P, Simmons DJ, Greenwood R, Peters TJ, Dayan CM: Partial substitution of thyroxine (T4) with triiodothyronine in patients on T4 replacement therapy: results of a large community-based randomized controlled trial. J Clin Endocrinol Metab 2005; 90:805-812.

40 Appelhof BC, Fliers E, Wekking EM, Schene AH, Huyser J, Tijssen JG, Endert E, Weert HCPM van, Wiersinga WM: Combined therapy with levothyroxine and liothyronine in two ratios, compared with levothyroxine monotherapy in primary hypothyroidism: a doubleblind, randomized, controlled clinical trial. J Clin Endocrinol Metab 2005;90:2666-2674.

41 Walsh JP, Shiels L, Lim EM, Bhagat CI, Ward LC, Stuckey BG, Dhaliwal SS, Chew GT, Bhagat MC, Cussons AJ: Combined thyroxine/ liothyronine treatment does not improve well-being, quality of life or cognitive function compared to thyroxine alone: a randomized controlled trial in patients with primary hypothyroidism. J Clin Endocrinol Metab 2003;88:4543-4550.

42 Clyde PW, Harari AE, Getka EJ, Shakir KM: Combined levothyroxine plus liothyronine compared with levothyroxine alone in primary hypothyroidism: a randomized controlled trial. JAMA 2003;290:2952-2958.

-43 Sawka AM, Gerstein HC, Marriott MJ, MacQueen GM, Joffe RT: Does a combination regimen of thyroxine (T4) and 3,5,3'-triiodothyronine improve depressive symptoms better than T4 alone in patients with hypothyroidism? Results of a double-blind, randomized, controlled trial. J Clin Endocrinol Metab 2003;88:4551-4555.

44 Bunevicius R, Kazanavicius G, Zalinkevicius R, Prange AJ Jr: Effects of thyroxine as compared with thyroxine plus triiodothyronine in patients with hypothyroidism. N Engl J Med 1999;340:424-429.

45 Rodriguez T, Lavis VR, Meininger JC, Kapadia AS, Stafford LF: Substitution of liothyronine at a 1:5 ratio for a portion of levothyroxine: effect on fatigue, symptoms of depression, and working memory versus treatment with thyroxine alone. Endocrine Pract 2005; 11:223-233.

46 Escobar-Morreale HF, Botella-Carretero JI, Gomez-Bueno M, Galan JM, Barrios V, Sancho J: Thyroid hormone replacement therapy in primary hypothyroidism: a randomized trial comparing L-thyroxine plus liothyronine with L-thyroxine alone. Ann Intern Med 2005;142:412-424. 
-47 Siegmund W, Spieker K, Weike AI, Giessmann T, Modess C, Dabers T, Kirsche G, Sanger E, Engel G, Hamm AO, Nauck M, Meng W: Replacement therapy with levothyroxine plus triiodothyronine (bioavailable molar ratio 14:1) is not superior to thyroxine alone to improve well-being and cognitive performance in hypothyroidism. Clin Endocrinol 2004;60:750-757.

-48 Bunevicius R, Jakubonien N, Jurkevicius R, Cernicat J, Lasas L, Prange AJ Jr: Thyroxine vs thyroxine plus triiodothyronine in treatment of hypothyroidism after thyroidectomy for Graves' disease. Endocrine 2002;18:129-133.

-49 Escobar-Morreale HF, Botella-Carretero JI, Escobar del Rey F, Morreale de Escobar G: Review: treatment of hypothyroidism with combinations of levothyroxine plus liothyronine. J Clin Endocrinol Metab 2005;90: 4946-4954.

50 Fadeyev VV, Morgunova TB, Melnichenko GA, Dedov II: Combined therapy with Lthyroxine and L-triiodothyronine compared to L-thyroxine alone in the treatment of primary hypothyroidism. Hormones 2010;9: 245-252.

51 Dayan CM, Panicker V: Novel insights into thyroid hormones from the study of common genetic variation. Nat Rev Endocrinol 2009;5:211-218.

-52 Arnaud-Lopez L, Usala G, Ceresini G, Mitchell BD, Pilia MG, Piras MG, Sestu N, Maschio A, Busonero F, Albai G, Dei M, Lai S, Mulas A, Crisponi L, Tanaka T, Bandinelli S, Guralnik JM, Loi A, Balaci L, Sole G, Prinzis A, Mariotti S, Shuldiner AR, Cao A, Schlessinger D, Uda M, Abecasis GR, Nagaraja R, Sanna S, Naitza S: Phosphodiesterase $8 \mathrm{~B}$ gene variants are associated with serum TSH levels and thyroid function. Am J Hum Genet 2008;82:1270-1280.

53 Shields BM, Freathy RM, Knight BA, Hill A, Weedon MN, Frayling TM, Hattersley AT, Vaidya B: Phosphodiesterase 8B gene polymorphism is associated with subclinical hypothyroidism in pregnancy. J Clin Endocrinol Metab 2009;94:4608-4612.

-54 Medici M, van der Deure WM, Verbiest M, Vermeulen SH, Hansen PS, Kiemeney LA, Hermus ARMM, Breteler MM, Hofman A, Hegedus L, Kyvik KO, den Heijer M, Uitterlinden AG, Visser TJ, Peeters RP: A large-scale association analysis of 68 thyroid hormone pathway genes with serum TSH and FT4 levels. Eur J Endocrinol 2011;164:781-788.

55 Taylor PN, Panicker V, Sayers A, Shields B, Iqbal A, Bremner AP, Beilby JP, Leedman PJ, Hattersley AT, Vaidya B, Frayling T, Evans J, Tobias JH, Timpson NJ, Walsh JP, Dayan CM: A meta-analysis of the associations between common variation in the $P D E 8 B$ gene and thyroid hormone parameters, including assessment of longitudinal stability of associations over time and effect of thyroid hormone replacement. Eur J Endocrinol 2011; 164:773-780.

- 56 Peeters RP, van Toor H, Klootwijk W, de Rijke YB, Kuiper GGJM, Uitterlinden AG, Visser TJ: Polymorphisms in thyroid hormone pathway genes are associated with plasma TSH and iodothyronine levels in healthy subjects. J Clin Endocrinol Metab 2003;88:2880-2888.

57 Panicker V, Cluett C, Shields B, Murray A, Parnell KS, Perry JRB, Weedon MN, Singleton A, Hernandez D, Evans J, Durant C, Ferucci L, Meltzer D, Saravanan P, Visser TJ, Ceresini G, Hattersley AT, Vaidya B, Dayan CM, Frayling TM: A common variation in deiodinase 1 gene DIO1 is associated with the relative levels of free thyroxine and free triiodothyronine. J Clin Endocrinol Metab 2008;93:3075-3081.

58 van der Deure WM, Hansen PS, Peeters RP, Uitterlinden AG, Fenger M, Kyvik KO, Hegedus L, Visser TJ: The effect of genetic variation in the type 1 deiodinase gene on the interindividual variation in serum thyroid hormone levels: an investigation in healthy Danish twins. Clin Endocrinol 2009;70:954-960.

59 Panicker V, Saravanan P, Vaidya B, Evans J, Hattersley AT, Frayling TM, Dayan CM: Common variation in the DIO2 gene predicts baseline psychological well-being and response to combination thyroxine plus triiodothyronine therapy in hypothyroid patients. J Clin Endocrinol Metab 2009;94: 1623-1629.

60 Peeters RP, van den Beld AW, Attalki H, van Toor H, de Rijke YB, Kuiper GGJM, Lamberts SWJ, Janssen JAMJL, UitterlindenAG, Visser TJ: A new polymorphism in the type II deiodinase gene is associated with circulating thyroid hormone parameters. Am J Physiol Endocrinol Metab 2005;289:E75-E81.

61 Torlantano M, Durante C, Torrente I, Crocetti U, Augello G, Ronga G, Montesano T, Travascio, Verriente A, Bruno R, Santini S, D’Arcangelo P, Dallapiccola B, Filetti S, Trischitta V: Type 2 deiodinase polymorphism (threonine 92 alanine) predicts L-thyroxine dose to achieve target thyrotropin levels in thyroidectomised patients. J Clin Endocrinol Metab 2008;93:910-913.

62 Heemstra KA, Hoftijzer HC, van der Deure WM, Peeters RP, Fliers E, Appelhof BC, Wiersinga WM, Corssmit EPM, Visser TJ, Smit JWA: Thr92Ala polymorphism in the type 2 deiodinase is not associated with T4 dose in athyroid patients or patients with Hashimoto thyroiditis. Clin Endocrinol 2009;71:279-283.

63 Kim BW, Bianco AC: For some, L-thyroxine replacement might not be enough: a genetic rationale. J Clin Endocrinol Metab 2009;94: 1521-1523.

64 Appelhof BC, Peeters RP, Wiersinga WM, Visser TJ, Wekking EM, Huyser J, Schene AH, Tijssen JGP, Hoogendijk WJG, Fliers E: Polymorphisms in type 2 deiodinase are not associated with well-being, neurocognitive functioning, and preference for combined thyroxine/3,5,3'-triiodothyronine therapy. J Clin Endocrinol Metab 2005;90:6296-6299.

65 van der Deure WM, Appelhof BC, Peeters RP, Wiersinga WM, Wekking EM, Huyser J, Schene AH, Tijssen JGP, Hoogendijk WJG, Visser TJ, Fliers E: Polymorphisms in the brain-specific thyroid hormone transporter OATP1C1 are associated with fatigue and depression in hypothyroid patients. Clin Endocrinol 2008;69:804-811.
66 Saravanan P, Siddique H, Simmons DJ, Greenwood R, Dayan CM: Twenty-four hour hormone profiles of TSH, free T3 and free T4 in hypothyroid patients on combined T3/T4 therapy. Exp Clin Endocrinol Diabetes 2007; 115:261-267.

67 Gullo D, Latina A, Frasca F, Le Moli R, Pellegriti G, Vigneri R: Levothyroxine monotherapy cannot guarantee euthyroidism in all athyreotic patients. PLoS ONE 2011; 6:e22552.

68 Alevizaki M, Mantzou E, Cimponeriu AT, Alevizaki CC, Koutras DA: TSH may not be a good marker for adequate thyroid hormone replacement therapy. Wien Klin Wochenschr 2005; 117:636-640.

-69 Bianco AC, Salvatore D, Gereben B, Berry MJ, Larsen PR: Biochemistry, cellular and molecular biology, and physiological roles of the iodothyronine selenodeiodinases. Endocr Rev 2002;23:38-89.

70 Toft AD, Beckett GJ: Thyroid function tests and hypothyroidism. Measurement of serum TSH alone may not always reflect thyroid status. Br Med J 2003;326:295-296.

71 Celi FS, Zemskova M, Linderman JD, Babar NI, Skarulis MC, Csako G, Wesley R, Costello R, Penzak SR, Pucino F: The pharmacodynamic equivalence of levothyroxine and liothyronine: a randomized, double blind, cross-over study in thyroidectomized patients. Clin Endocrinol 2010;72:709-715.

72 Read DG, Hays MT, Hershman JM: Absorption of oral thyroxine in hypothyroid and normal man. J Clin Endocrinol Metab 1970; 30:798-799.

73 Hasselstrom K, Siersbaek-Nielsen K, Lumholtz IB, Faber J, Kirkegaard C, Friis T: The bioavailability of thyroxine and 3,5,3'triiodothyronine in normal subjects and in hyper- and hypothyroid patients. Acta Endocrinol (Copenh) 1985;110:483-486.

-74 Hays MT, Nielsen KRK: Human thyroxine absorption: age effects and methodological analyses. Thyroid 1994;4:55-64.

75 Woeber KA: Treatment of hypothyroidism; in Braverman LE, Utiger RD (eds): Werner and Ingbar's The Thyroid, a Fundamental and Clinical Text, ed 9. Philadelphia, Lippincott Williams \& Wilkins, 2005, pp 864869.

-76 Henneman G, Docter R, Visser TJ, Postema PT, Krenning EP: Thyroxine plus low-dose, slow-release triiodothyronine replacement in hypothyroidism. Thyroid 2004;14:271275.

77 Russell W, Harrison RF, Smith N, Darzy K, Shalet S, Weetman AP, Ross RJ: Free triiodothyronine has a distinct circadian rhythm that is delayed but parallels thyrotropin levels. J Clin Endocrinol Metab 2008;93:23002306.

78 Laurberg P: Patients on appropriate T4 replacement are as content as they would be on any thyroid hormone (letter to the editor). J Clin Endocrinol Metab 2004;89:2507.

79 Sawka AM, Gerstein HG: Authors' response. Patients on appropriate T4 replacement are as content as they would be on any thyroid hormone (letter to the editor). J Clin Endocrinol Metab 2004;89:2507-2508. 